\section{Feeding effectiveness of Megaphobema mesomelas (Araneae, Theraphosidae) on two prey types}

\author{
Scott Kosiba \\ 11438 S. 26th Street, Vicksburg, \\ MI 49097, USA
}

\section{Pablo Allen}

Council on International Educational Exchange, Monteverde, Puntarenas 43-5655, Costa Rica

\section{Gilbert Barrantes}

Escuela de Biología, Universidad de Costa Rica, Ciudad Universitaria Rodrigo Facio,

San José, Costa Rica

email: gilbert.barrantes@gmail.com

\section{Summary}

\begin{abstract}
Prey selection is essential for individual fitness; therefore, it would be expected that a predator would select prey of a higher rank (energy/time) when exposed to prey of differing quality. In this paper, we compare the feeding effectiveness (biomass consumed/time) of Megaphobema mesomelas (O. P.-Cambridge, 1892) in captivity, and the preference between two prey types: beetles and crickets. Spiders are more effective when feeding on crickets. The heavy exoskeleton of beetles increases preyhandling time in order to access a relatively smaller amount of edible tissue. Effectiveness also increases with spider and prey size (mass), with larger spiders feeding more effectively on larger prey. Spiders show a strong preference for feeding upon crickets over beetles when both prey types are offered at the same time.
\end{abstract}

\section{Introduction}

In spiders, rate of energy intake is directly related to growth and reproduction (Kessler 1971; Anderson 1974; Briceño 1987; Foelix 1996). This rate is affected by prey availability, capture efficiency, handling time, ingestingdigesting time, energy contained in the prey package, and silk and energy required to subdue a prey. These factors vary greatly across both prey types and spider size within each spider species (Robinson \& Robinson 1973; Eberhard et al. 2006; Weng et al. 2006; Morse 2007). For instance, beetles are a well-protected prey and spiders that crush the prey possibly require more time and energy to access their tissues. Ants are aggressive and dangerous prey, some of which could kill a spider, and which demand more time and silk, in the case of silk wrapping araneomophs, to subdue than do flies, which have relatively soft exoskeletons (Barrantes \& Eberhard 2007). Thus, considering the variation in prey features, it is expected that, within the context of optimal foraging, spiders may make decisions to maximize their energy intake (LeSar \& Unzicker 1978; Uetz \& Hartsock 1987; Toft \& Wise 1999; Morse 2007).

Theraphosid spiders are sit-and-wait predators with retreats in the ground or on aerial substrates (Stradling 1994; Locht et al. 1999). They are primarily nocturnal hunters that wait at or near the entrance of the tunnel for passing prey. Prey are likely detected by vibrations produced as they walk near the tunnel or when they contact threads near the tunnel opening (Coyle 1986). Prey detection triggers the spider's fast and lethal attack (Barrantes \& Eberhard 2007). Subsequent prey wrapping occurs when prey are large and difficult to handle and/or when several prey are attacked in succession, often after the prey's movements cease (Barrantes \& Eberhard 2007). Prey is then progressively crushed, enzymes are regurgitated, and the liquefied tissue is sucked and ingested. Feeding continues until the prey becomes a small pellet of tiny pieces of indigestible prey parts (Gertsch 1949).

The decision a sit-and-wait predator makes on whether to attack a given prey may depend on several types of information, including: risk of being harmed, time needed to handle and feed on it, energy reward, degree of hunger, and experience (Morse 2007). In this study, we measured feeding effectiveness (defined as $\mathrm{g}$ of biomass consumed/feeding time) and preference of the Red-Knee Tarantula Megaphobema mesomelas on two prey types: scarab beetles in the family Scarabaeidae, and crickets in the family Gryllidae; likely a common prey of theraphosids (Yáñez \& Floater 2000; Peréz-Miles et al. 2005). Although the exoskeleton of crickets on the legs and the dorsal part of the thorax is relatively thick, the exoskeleton of the beetles is much thicker and harder. For a spider that feeds by crushing its prey, the energy used to break a hard beetle exoskeleton is possibly higher and the net biomass gained (digestible tissue) is possibly lower than for a cricket. We first examined the time M. mesomelas required to feed on beetles and crickets and then tested whether this spider was able to choose between the two prey types. We expected that when both prey were offered at the same time, spiders would feed on prey that gave them a higher biomass reward. Prey choice has been extensively explored in some web spiders and crab spiders (LeSar \& Unzicker 1978; Morse 2007), but very little is known on this topic from theraphosids.

\section{Methods}

We collected $10 \mathrm{M}$. mesomelas adult females from burrows in Cerro Plano, Monteverde, Puntarenas province, Costa Rica $\left(84^{\circ} 47^{\prime} \mathrm{W}, 10^{\circ} 18^{\prime} \mathrm{N} ; 1450 \mathrm{~m}\right.$ a.s.1.). The tarantulas were drawn from their burrows by scratching near the entrance of the burrow with a small twig to simulate vibrations produced by prey. They were then collected and placed in individual plastic containers for transportation to the laboratory of the University of Georgia in Monteverde, where each spider was placed in a separate terrarium $(48 \mathrm{~cm}$ $\times 32 \mathrm{~cm} \times 32 \mathrm{~cm}$ ) and maintained at $25-27^{\circ} \mathrm{C}$ and $70-80 \%$ relative humidity with water $a d$ lib. We covered the bottom of each terrarium with whitish cardboard rather than soil or other, more natural, substrate in order to facilitate observation of the spider's movements and collecting prey remains. Furthermore, this substrate serves to control for possible differences in prey detection due to differences in vibration transmission through an irregular substrate during feeding experiments. During the day, we covered the terrarium with opaque paper to avoid direct light on the spider. Each spider was weighed as an estimation of its size, and maintained in the terrarium for five days prior to feeding trials. All feeding trials were conducted at night with illumination from a fluorescent light $3 \mathrm{~m}$ away, after removing the opaque paper. 

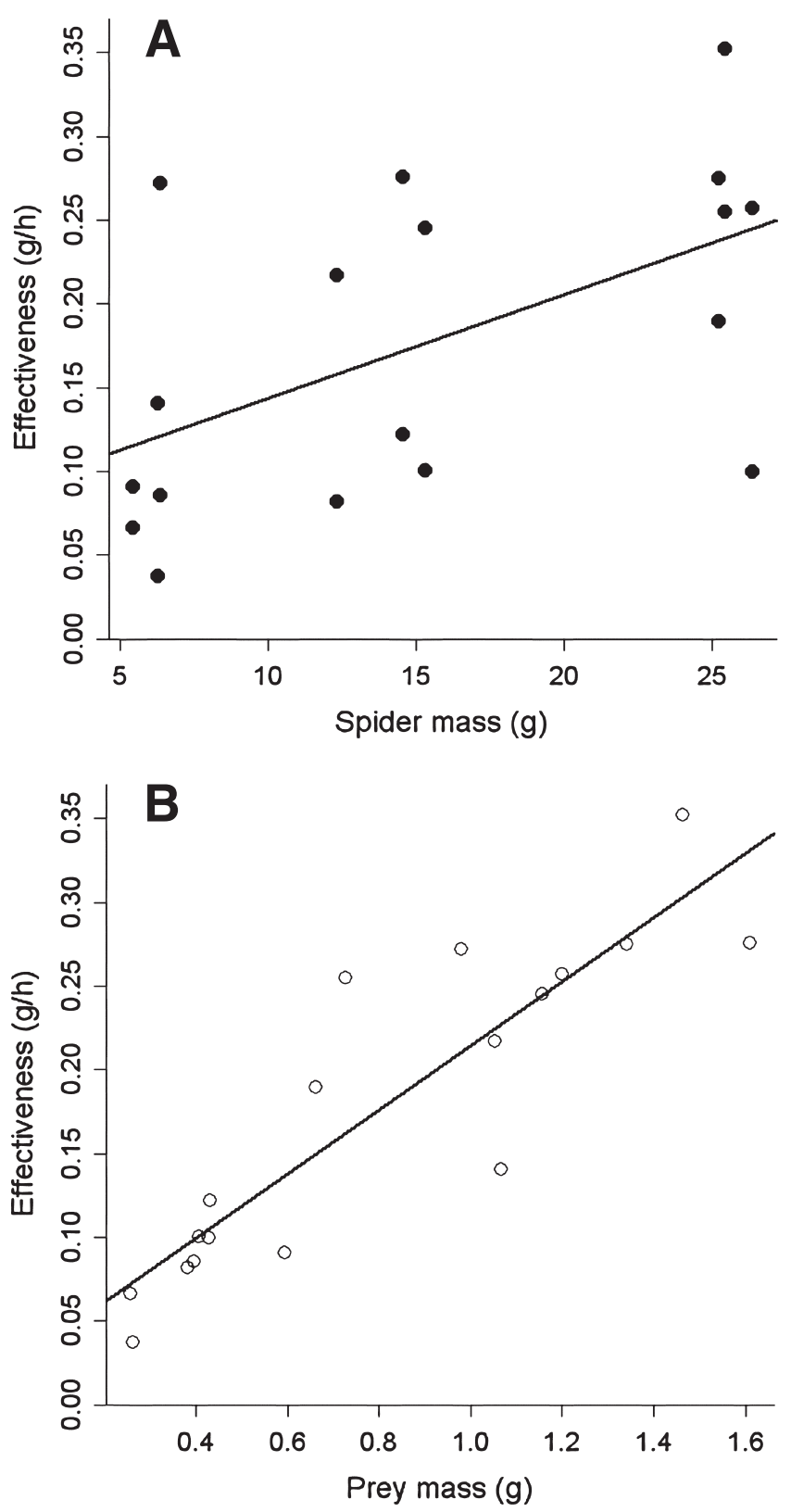

Fig. 1: Increase in feeding effectiveness ( $\mathrm{g}$ biomass/time). $\mathbf{A}$ in relation to spider, not adjusted for prey mass; $\mathbf{B}$ in relation to live prey mass, not adjusted for spider mass.

Voucher specimens of the spiders were deposited in the Museo de Zoología, Universidad de Costa Rica.

To measure feeding time and biomass consumed, we randomly assigned spiders to prey type, and each spider was offered three beetles and three crickets. Not all spiders fed on the six prey offered. If a spider did not attack a prey item offered within $1 \mathrm{~h}$, then this prey was removed, and no other prey was offered until the next trial. Both prey types are common in the area where the spiders were collected; large quantities of the beetles used in this study emerged from under ground as adults during the rainy season, and crickets are leaf-feeders in the herbaceous layer. To determine feeding effectiveness, we weighed $( \pm 0.001 \mathrm{~g})$ each prey alive and placed it $8 \mathrm{~cm}$ in front of the spider. Feeding time was measured from the initial attack and capture to the moment the prey remains were dropped by the tarantula. The pellet of prey remains was immediately collected and weighed to determine the total biomass consumed by the spider; this procedure overestimates the net biomass due to the water loss during feeding, but it is useful to compare prey in similar conditions (Southwood 1978). We calculated the mean feeding effectiveness for each prey type for each spider and used means for all analyses. We then compared the proportion of the biomass consumed from both prey types (mass consumed/initial mass) using a Wilcoxon paired test. Additionally, we compared the mass discarded (mass discarded/initial mass) by the spiders of each prey type, and the handling or consuming time (minutes that a spider took to consume one mg of insect mass: $\mathrm{min} / \mathrm{mg}$ ) using, in both cases, the Wilcoxon paired test. To test feeding effectiveness of the same group of spiders on two prey types we used a saturated analysis of covariance (i.e. all factors and all interactions tested) implemented in R (R Development Core Team 2008). In this model, prey type was included as the predictor factor of effectiveness, and the spider mass and prey mass as covariates. Thus, the effects of prey size and spider size on effectiveness were separated from the preytype effect.

We used the same ten spiders to test prey-type preference. We selected a beetle and a cricket of similar body size. We measured total length and dry weight (dry at $40^{\circ} \mathrm{C}$ for 6 days) of a sample of each prey type, and prey did not differ in size (beetles: mean $=19.02 \mathrm{~mm}, \mathrm{SD}=3.48$; crickets: mean $=22.25 \mathrm{~mm}, \mathrm{SD}=3.75 ; \mathrm{t}=1.99$, $\mathrm{df}=18, \mathrm{P}=0.07$ ) nor dry weight (beetles: mean $=0.135 \mathrm{~g}, \mathrm{SD}=0.100$; crickets: mean $=0.095 \mathrm{~g}, \mathrm{SD}=0.043 ; \mathrm{t}=1.18$, $\mathrm{df}=18$, $\mathrm{P}=0.26$ ). For these experiments, we placed a beetle and a cricket in a freezer at $-20^{\circ} \mathrm{C}$ for $1 \mathrm{~min}$. Prey were then withdrawn and, as soon as we perceived the first (nearly imperceptible) movements, both insects were placed simultaneously at about $8 \mathrm{~cm}$ facing each tarantula. Most of the time, beetles were first to move after withdrawing both prey from the freezer; dead prey were not used in any experiment. In this stage of dormancy, we presumed that the spider's prey selection was based primarily on feeding preference, rather than on prey movements. We determined spider preference by examining which prey was consumed rather than which prey the spider first approached. For example, if a spider first approached prey A, but rejected it, then approached and consumed prey $\mathrm{B}$, then $\mathrm{B}$ was registered as the preferred prey. We used a binomial test to analyse prey type preference.

\section{Results}

Spiders fed on 54 prey: 25 beetles and 29 crickets, and they consumed proportionally more biomass from crickets (median $=0.86 \mathrm{~g}$, range $=0.67-0.92)$ than from beetles (median $=0.76 \mathrm{~g}$, range $=0.59-0.91) \quad$ (Wilcoxon paired test: $\mathrm{P}=0.03, \mathrm{~N}=9$ ); consequently, spiders discarded a larger amount of mass from beetles (median $=0.27 \mathrm{~g}$, range $=0.09-0.41)$ than from crickets (median $=0.13 \mathrm{~g}$, range $=0.09-0.34) \quad$ (Wilcoxon paired test: $\mathrm{P}=0.03$, $\mathrm{N}=9$ ). Spiders also spent more time handling beetles (median $=0.54 \mathrm{~min} / \mathrm{mg}$, range $=0.20-1.02)$ than crickets (median $=0.22 \mathrm{~min} / \mathrm{mg}$, range $=0.15-0.59)$. The spider's feeding effectiveness ( $\mathrm{g}$ biomass/feeding hour) was significantly higher for crickets (mean $=0.24 \mathrm{~g}, \mathrm{SD}=0.08$ ) than 
for beetles $\quad($ mean $=0.12 \mathrm{~g}, \quad \mathrm{SD}=0.07) \quad\left(\mathrm{F}_{(1,10)}=39.97\right.$, $\mathrm{P}=0.00008$ ), and prey type explained $44 \%$ of the total variation in feeding effectiveness. Effectiveness also increased with both spider mass $\left(\mathrm{F}_{(1,10)}=27.67, \mathrm{P}=0.0004\right)$ and insect mass $\left(\mathrm{F}_{(1,10)}=10.91, \mathrm{P}=0.008\right.$; Fig. 1$)$, explaining $30 \%$ and $12 \%$, respectively, of the total variation. Interactions between covariates and between covariates and prey type were not significant.

In the experiment on prey selection, spiders consumed eight crickets and only one beetle (Binomial test: $\mathrm{P}=0.03$ ). One spider fed on neither of the two prey offered. Spiders apparently used chemical signals, though mechanical signals cannot be entirely ruled out, for prey identification Four spiders first approached the beetle, gently touched it with the pedipalps, then walked towards the cricket to deliver its lethal attack and then fed on it; two other spiders first killed the beetle, one of them dropped it, and then attacked and fed on the cricket. The other three spiders approached the cricket first, killed it, and then fed on it.

\section{Discussion}

The net rate of energy intake (energy intake/time) in spiders depends upon at least five different factors: patch quality, prey quality, searching (or waiting) time, and handling time (Morse 2007). Once prey is subdued, these factors are reduced to prey quality and handling time, and it is common that prey quality is positively correlated with handling time (Pyke et al. 1977). However, in this study, handling time was higher for beetles because a beetle demanded longer time for M. mesomelas to access a smaller amount of tissue due to its heavy, inedible exoskeleton. The feeding effectiveness was higher for large spiders feeding on large prey (Fig. 1). Smaller insects have a larger exoskeleton in relation to its biomass (body surface increases to a power of approximately $2 / 3$ relative to its volume). It is also possible that it is more difficult for a large spider to handle pieces of small insects.

The strong preference showed by $M$. mesomelas for crickets over beetles in this study was correlated with the larger rate of biomass (energy) intake obtained by preying on crickets. This is supported by the fact that more spiders first approached beetles and then crickets, possibly because beetles began to move before crickets, but they ended up feeding on crickets rather than beetles. The preference of spiders to feed on crickets is due possibly to the result of their experience during the experiment, and possibly to their previous experience in nature, as has been demonstrated in other spiders (Punzo 2002; Morse 2007).

In nature, $M$. mesomelas probably has a more diverse diet, as in other Theraphosidae (Gertsch 1949; Stradling 1994; Pérez-Miles et al. 2005). Opportunities to choose among prey, as in our attempts, are very unlikely, as prey encounters are expected to be very infrequent. However, this study showed that when this spider is faced with two prey of different quality, it is capable of selecting the prey with the larger amount of biomass (possibly energy) reward, showing the ability to adjust advantageously to this unusual condition.

\section{Acknowledgements}

We thank William Eberhard, Fernando G. Costa, and two anonymous reviewers for valuable comments on the manuscript, CIEE Monteverde for logistical support, and the University of Georgia for allowing use of the laboratory space. This study was partially supported by the Vicerrectoría de Investigación, Universidad de Costa Rica.

\section{References}

ANDERSON, J. F. 1974: Responses to starvation in the spiders Lycosa lenta Hentz and Filistata hibernalis (Hentz). Ecology 55: 576-585.

BARRANTES, G. \& EBERHARD, W. G. 2007: The evolution of prey wrapping behaviour in spiders. Journal of Natural History 41 1631-1658.

BRICEÑO, R. D. 1987: How spiders determine clutch size. Revista de Biología Tropical 35: 25-29.

EBERHARD, W. G., BARRANTES, G. \& WENG, J. L. 2006: Tie them up tight: wrapping by Philoponella vicina spiders breaks, compresses and sometimes kills their prey. Naturwissenschaften 93: 251-254.

COYLE, F. A. 1986: The role of silk in prey capture. In Shear W. A. (ed.), Spiders: webs, behavior, and evolution. Stanford, CA: Stanford University Press: 269-305.

FOELIX, R. F. 1996: Biology of spiders. 2nd edition. New York: Oxford University Press.

GERTSCH, W. J. 1949: American spiders. New Jersey: Van Nostrand.

KESSLER, A. 1971: Relation between egg production and food consumption in species of the genus Pardosa (Lycosidae, Araneae) under experimental conditions of food-abundance and foodshortage. Oecologia 8: 93-109.

LESAR, C. D. \& UNZICKER, J. D. 1978: Life history, habits, and prey preferences of Tetragnatha laboriosa (Araneae: Tetragnathidae). Environmental Entomology 7: 879-884.

LOCHT, A., YÁÑEZ, M. \& VAZQUEZ, I. 1999: Distribution and natural history of Mexican species of Brachypelma and Brachypelmides (Theraphosidae, Theraphosinae) with morphological evidence for their synonymy. Journal of Arachnology 27: 196-200.

MORSE, D. M. 2007. Predator upon a flower. Life history and fitness in a crab spider. Cambridge, MA: Harvard University Press.

PÉREZ-MILES, F., COSTA, F. G., TOSCANO-GADEA, C. \& MIGNONE, A. 2005: Ecology and behaviour of the 'road tarantulas' Eupalaestrus weijenberghi and Acanthoscurria suina (Araneae, Theraphosidae) from Uruguay. Journal of Natural History 39: 483-498.

PUNZO, F. 2002: Food imprinting and subsequent prey preference in the lynx spider, Oxyopes salticus (Araneae: Oxyopidae). Behavioural Processes 58: 177-181.

PYKE, G. H, PULliAM, H. R. \& CHARNOV, E. L. 1977: Optimal foraging: a selective review of theory and tests. Quarterly Review of Biology 52: 137-154.

R DEVELOPMENT CORE TEAM 2008: R: language and environment for statistical computing. Vienna, Austria: $\mathrm{R}$ Foundation for Statistical Computing.

ROBINSON, M. H. \& ROBINSON, B. 1973: Ecology and behavior of the giant wood spider Nephila maculata (Fabricius) in New Guinea. Smithsonian Contributions to Zoology 149: 1-76.

SOUTHWOOD, T. R. E. 1978: Ecological methods. London: WileyBlackwell.

STRADLING, D. J. 1994: Distribution and behavioral ecology of an arboreal 'tarantula' spider in Trinidad. Biotropica 26: 84-97.

TOFT, S. \& WISE, D. H. 1999: Growth, development and survival of a generalist predator fed single and mixed-species diets of different quality. Oecologia 119: 191-197.

UETZ, G. W. \& HARTSOCK, S. P. 1987: Prey selection in an orb-weaving spider: Micrathena gracilis (Araneae: Araneidae). Psyche 94: 103-116.

WENG, J. L., BARRANTES, G. \& EBERHARD, W. G. 2006: Feeding by Philoponella vicina (Araneae, Uloboridae) and how uloborids lost their venom glands. Canadian Journal of Zoology 84: 1752-1762.

YÁÑEZ, M. \& FLOATER, G. 2000: Spatial distribution and habitat preference of the endangered tarantula, Brachypelma klaasi (Araneae: Theraphosidae) in Mexico. Biodiversity Conservation 9: 795-810. 